\title{
Prevalence of brachial plexus injuries in patients with scapular fractures: A National Trauma Data Bank review
}

\author{
Edward Chamata $\mathrm{BA}^{1}$, Raman Mahabir $\mathrm{MD}^{1,2}$, Daniel Jupiter $\mathrm{PhD}^{1,2}$, Robert A Weber $\mathrm{MD}^{1,2}$
}

\begin{abstract}
E Chamata, R Mahabir, D Jupiter, RA Weber. Prevalence of brachial plexus injuries in patients with scapular fractures: A National Trauma Data Bank review. Plast Surg 2014;22(4):246-248.
\end{abstract}

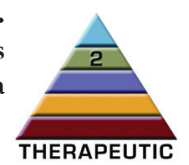

BACKGROUND: Studies investigating the prevalence of brachial plexus injuries associated with scapular fractures are sparse, and are frequently limited by small sample sizes and often restricted to single-centre experience. OBJECTIVE: To determine the prevalence of brachial plexus injuries associated with scapular fractures; to determine how the prevalence varies with the region of the scapula injured; and to assess which specific nerves of the brachial plexus were involved.

METHODS: The present study was a retrospective review of data from the National Trauma Data Bank over a five-year period (2007 to 2011).

RESULTS: Of 68,118 patients with scapular fractures, brachial plexus injury was present in $1173(1.72 \%)$. In patients with multiple scapular fractures, the prevalence of brachial plexus injury was $3.12 \%$, and ranged from $1.52 \%$ to $2.22 \%$ in patients with single scapular fractures depending on the specific anatomical location of the fracture. Of the 426 injuries with detailed information on nerve injury, 208 (49\%) involved the radial nerve, $113(26.5 \%)$ the ulnar nerve, $65(15 \%)$ the median nerve, $36(8.5 \%)$ the axillary nerve and four $(1 \%)$ the musculocutaneous nerve.

CONCLUSION: The prevalence of brachial plexus injuries in patients with scapular fractures was $1.72 \%$. The prevalence was similar across anatomical regions for single scapular fracture and was higher with multiple fractures. The largest percentage of nerve injuries were to the radial nerve.

Key Words: Brachial plexus; National trauma data bank; Scapula; Scapular fracture

Capular fractures comprise $3 \%$ to $5 \%$ of all shoulder girdle fractures, $\checkmark$ while accounting for $<1 \%$ of all fractures (1). Fracture of the scapula usually occurs after high-energy trauma; thus, approximately $90 \%$ of patients have concomitant injuries (2,3). In a previous study investigating scapular fractures, McGahan et al (4) found that at four weeks follow-up after injury, complaints pertaining to the shoulder, such as decreased range of motion and pain, were limited to the subset of patients who experienced neurological deficits in addition to their scapular fracture. That article emphasized the importance of early recognition and treatment of brachial plexus injuries to improving patient outcomes. The purpose of the present investigation was to study a large number of patients with different types of scapular fractures to determine the prevalence of concurrent brachial plexus injuries; to determine how prevalence varies in different regions of the scapula injured; and to assess which specific nerves of the brachial plexus were injured. This information may help to guide clinical suspicion and increase awareness of this often devastating injury. The National Trauma Data Bank (NTDB), currently the largest trauma registry in the United States (US), containing data on $>5$ million cases from $>900$ registered US trauma centres, was used to gather the data (5).

\section{La prévalence de lésions du plexus brachial chez les patients ayant des fractures scapulaires : l'analyse d'une banque nationale de données sur les traumatismes}

HISTORIQUE : Il existe peu d'études sur la prévalence de lésions du plexus brachial liées aux fractures scapulaires. Celles qui existent sont souvent limitées par le petit échantillon et sont restreintes à l'expérience d'un seul centre.

OBJECTIF : Déterminer la prévalence de lésions du plexus brachial associées à des fractures scapulaires, établir la variation de la prévalence selon la région de l'omoplate qui est touchée et évaluer les nerfs du plexus brachial qui sont atteints.

MÉTHODOLOGIE : La présente analyse rétrospective évaluait les données de la National Trauma Data Bank sur une période de cinq ans (2007 à 2011).

RÉSULTATS : Chez les 68118 patients ayant des fractures scapulaires, $1173(1,72 \%)$ avaient une lésion du plexus brachial. Chez les patients ayant des fractures scapulaires multiples, la prévalence de lésions du plexus brachial s'élevait à 3,12\%, et elle variait entre $1,52 \%$ et 2,22 \% chez ceux qui en avaient une seule, selon la région anatomique où elle était située. De l'information détaillée était fournie sur la lésion nerveuse de 426 blessures : 208 (49\%) touchaient le nerf radial, 113 (26,5\%), le nerf cubital, $65(15 \%)$, le nerf médian, 36 (8,5\%), le nerf axillaire, et quatre (1\%), le nerf musculocutané.

CONCLUSION : La prévalence de lésions du plexus brachial s'élevait à $1,72 \%$ chez les patients ayant des fractures scapulaires. Cette prévalence était similaire entre les régions anatomiques lorsqu'il s'agissait d'une fracture scapulaire simple, et plus élevée lorsque les fractures étaient multiples. Les lésions nerveuses touchaient surtout le nerf radial.

\footnotetext{
${ }^{1}$ Texas AEM Health Sciences Center College of Medicine; ${ }^{2}$ Division of Plastic Surgery, Department of Surgery, Baylor Scott and White Health, Temple, Texas USA

Correspondence: Mr Edward Chamata, Texas AEMM Health Sciences Center College of Medicine, 2401 South 31st Street, Temple,

Texas 76508, USA. Telephone 832-818-3541,e-mail chamata@medicine.tamhsc.edu
} 
TABLE 1

Prevalence of brachial plexus injuries in scapular fractures

\begin{tabular}{lcrc}
\hline $\begin{array}{l}\text { Scapular fracture } \\
\text { location }\end{array}$ & $\begin{array}{c}\text { ICD-9 code (open } \\
\text { and closed fracture) }\end{array}$ & $\begin{array}{c}\text { Scapular } \\
\text { fractures, } \mathbf{n}\end{array}$ & $\begin{array}{c}\text { Brachial plexus } \\
\text { injuries*, } \mathbf{n}(\%)\end{array}$ \\
\hline Unspecified location & 811.00 and 811.10 & 39,314 & $597(1.52)$ \\
Acromial process & 811.01 and 811.11 & 2908 & $62(2.13)$ \\
Coracoid process & 811.02 and 811.12 & 2166 & $48(2.22)$ \\
Glenoid cavity or neck & 811.03 and 811.13 & 6361 & $122(1.92)$ \\
Body or spine & 811.04 and 811.14 & 14,769 & $263(1.78)$ \\
Multiple fracture & 811.99 & 2600 & $81(3.12)$ \\
Total & & 68,118 & $1173(1.72)$ \\
\hline
\end{tabular}

$*(P<0.00001) . I C D-9$ International Classification of Diseases, Ninth Revison

Prevalence was computed as the percentage of incidents with associated brachial plexus injury. The relationship of scapular fracture location and occurrence of brachial plexus injury was assessed using the $\chi^{2}$ test; $\mathrm{P}<0.05$ was considered to be statistically significant.

To investigate which main branch of the brachial plexus was most frequently injured in conjunction with a scapular fracture, attention was restricted to injuries coded specifically for the five main branches of the brachial plexus, to the exclusion of the other possible nerve injuries.

All statistical analysis was performed using the $\mathrm{R}$ statistical package (R, Developmental, Core, Team. R: A Language and Environment for Statistical Computing, 2013. http://www.R-project.org)

\section{RESULTS}

In a five-year period (2007 to 2011), scapular fractures were observed in 68,118 patient incidents. Fractures were coded as being to a specific anatomical location in 26,204 (38.5\%). The other 41,914 (61.5\%) fractures were coded as 'unspecified location' (39,314 [57.7\%]) or 'multiple fractures' (2600 [3.8\%]) (Table 1). Of the 26,204 scapular fractures assigned to a specific anatomical location, fractures of the body or spine comprised the largest group (14,769 fractures). Fractures of the glenoid cavity or neck of the scapula comprised the second largest group (6361 fractures). Fractures of the acromial process comprised 2908 fractures, while those of the coracoid process comprised 2166 fractures (Figure 1).

Brachial plexus injury was present in 1173 (1.72\%) of the 68,118 patients. The distribution of brachial plexus injuries throughout different scapular regions is summarized in Table 1 . Of the 1173 brachial plexus injury incidents, 83 were coded under multiple ICD-9 codes: 70 of these were coded under two categories, nine were coded under three and three were coded under $\geq 4$. Thus, summing the brachial plexus injuries within each brachial plexus injury category yielded a total number of injuries slightly higher than the 1173 injury incidents (Table 2).

While 747 brachial plexus injury incidents were not categorized specifically as injuries to the five main branches of the brachial plexus, 426 were. Of the 426 injuries with detailed information on the nerve injury, 208 involved the radial nerve, 113 the ulnar nerve, 65 the median nerve, 36 the axillary and four the musculocutaneous (Figure 2) nerves.

\section{DISCUSSION}

Studies have reported up to $90 \%$ concomitant injury rates in patients with scapular fractures; the most frequently reported was the ipsilateral rib fracture $(40 \%)(4,6,7)$. High-energy traumas have the potential to cause several life-threatening injuries such as pneumothorax, closed head injury, arterial injury, pulmonary contusion, and splenic or liver laceration $(4,8)$. With mortality rates as high as $15 \%$ from these injuries $(8,9)$, recognition and treatment of the scapular fracture may be delayed to address life-threatening injuries. However, scapular fractures can cause devastating long-term neurological deficits and possibly even permanent disability of the shoulder and upper extremity, with the most common neurological condition being an ipsilateral brachial plexus lesion $(4,8,9)$.

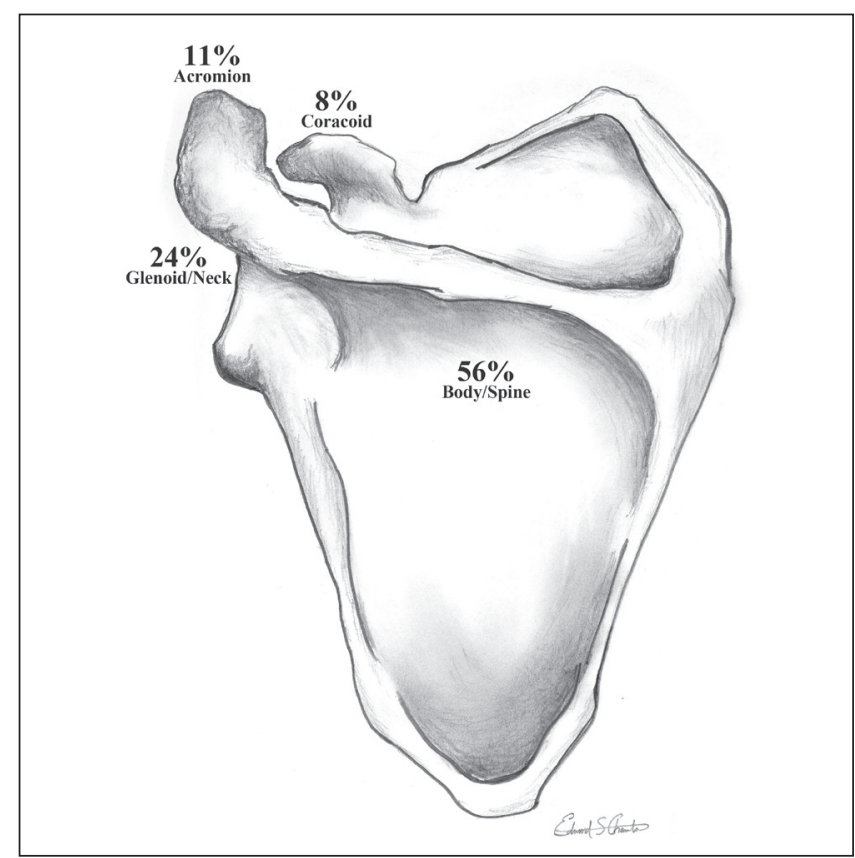

Figure 1) Percentage distribution of the 26,204 scapular fractures according to anatomical location according to International Classification of Diseases, Ninth Revision code

Literature describing the prevalence of brachial plexus injuries associated with scapular fractures is sparse, frequently limited by small sample sizes and often restricted to patients from a single centre. The reported prevalence of brachial plexus injury associated with fractures of the scapula ranged from $5 \%$ to $13 \%$ in these earlier studies $(4,6,10)$, with the largest study investigating 121 patients in a single facility (4). Our review of the NTDB revealed 1173 brachial plexus injuries in 68,118 patients with scapular fractures - a prevalence of $1.72 \%$. This percentage is significantly lower than that reported in previous studies. Although these earlier reports are informative, our study explored data pooled from numerous trauma centres nationwide, with a significantly larger number of patients.

Over the past 30 years, only a handful of studies have used the concept of dividing the scapula into its anatomical regions $(4,6,7)$. Similar to our study, Scavenius and Sloth (7), Armstrong and Van der Spuy (6) and McGahan et al (4) reviewed 18, 62 and 121 patients, respectively, with scapular fractures according to their anatomical distribution. Scavenius and Sloth (7) found that $56 \%$ of the fractures were located on the body of the scapula, while $44 \%$ were of the glenoid cavity or neck of the scapula. Armstrong and Van der Spuy (6) found that $61 \%$ of the fractures were of the body or spine of the scapula, $27 \%$ were of the glenoid cavity or neck of the scapula, $9 \%$ were of the acromion and $3 \%$ were of the coracoid process (6). Finally, McGahan et al (4) found that $49 \%$ of fractures were of the body or spine of the scapula, $36 \%$ were of the glenoid cavity or neck, $8 \%$ were of the acromion and $7 \%$ were of the coracoid. Our data from the 26,204 patients demonstrated a similar distribution.

An earlier study investigating 11 acromial fractures noticed that $67 \%$ were associated with a brachial plexus injury and, thus, concluded that brachial plexus injuries occurring alongside a scapular fracture are usually caused by acromial fractures $(4,6)$. Our finding would appear to contradict those original reports in that of 2908 acromial fractures, only $2.13 \%$ had associated brachial plexus injury. Similarly, the prevalence of brachial plexus injuries in other scapular locations appeared to be fairly uniform, ranging from $1.78 \%$ to $2.22 \%$. Interestingly, the prevalence of brachial plexus injuries rose to $3.12 \%$ when multiple scapular fractures were noted. 
TABLE 2

Distribution of nerve injuries in brachial plexus injuries among patients with scapular fractures

\begin{tabular}{llc}
\hline Brachial plexus injury & ICD-9 code(s) & Injuries, $\mathbf{n}$ \\
\hline Axillary nerve & 955.0 & 36 \\
Median nerve & $955.1,354.1$ & 65 \\
Ulnar nerve & 955.2 & 113 \\
Radial nerve & $955.3,354.3$ & 208 \\
Musculocutaneous nerve & 955.4 & 4 \\
Cutaneous sensory nerve of & 955.5 & 4 \\
$\quad$ upper limb & & 52 \\
Cervical root injury & 953.0 & 66 \\
Other specified nerve & 955.7 & 7 \\
Multiple nerves & $955.8,953.8$ & 721 \\
Unspecified/general brachial & $955.9,953.9,953.4,353.0$ & \\
$\quad$ plexus injury & & \\
Total brachial plexus injury & 1173 & \\
$\quad$ incidents & &
\end{tabular}

ICD-9 International Classification of Diseases, Ninth Revison

In a study involving 39 patients with a scapular fracture, McGinnis and Denton (11) noticed that one of their patients had an associated radial nerve injury. A separate case report discussed a patient experiencing an isolated axillary nerve injury in association with an acromial fracture (12). To our knowledge, these are the only two studies that name the specific brachial plexus injury associated with a scapular fracture. We found that of 426 injuries (with detailed information available), the radial nerve was the most commonly injured, comprising nearly one-half of main branch injuries, followed by ulnar nerve injuries, accounting for nearly one-quarter of main branch injuries. Therefore, if a brachial plexus injury is suspected, special attention should be devoted to radial nerve and ulnar nerve deficits because they account for nearly $75 \%$ of main branch lesions.

The most obvious limitation to our study was that the NTDB is composed of data from large trauma centres that treat more severely injured patients (5). Due to this higher injury severity and potentially life-threatening injuries, brachial plexus injuries may be missed during the primary and secondary survey. Some studies have shown that the severity of the patient's presentation is inversely related to the detection of secondary trauma (5). This is partly due to the 'satisfaction of search', which is the propensity to overlook less obvious conditions after detecting a more apparent injury $(13,14)$. In addition, because a large number of patients with scapular fractures are unconscious at the time of presentation, a brachial plexus examination must wait and, thus, can be forgotten later in a patient's hospital course.

A second limitation to our study was that some ICD-9 codes that account for a substantial percentage of the total brachial plexus injuries involve brachial plexus lesions that were not further classified based on the specific nerve injured. For example, one of these categories, ICD-9 code 953.4 "brachial plexus injury", is a general category that does not provide any information about what specific nerve of the brachial plexus was injured. All ICD-9 codes that comprise this 'general/ unspecified injury' category are listed in Table 2 . The number of injuries within these general codes were very informative in our discussion of prevalence of brachial plexus injuries in patients with scapular fractures; however, they were not useful in exploring which specific nerves were most affected if a brachial plexus injury were to occur.

\section{CONCLUSION}

The prevalence of brachial plexus injuries $(1.72 \%)$ was significantly lower than previously reported in patients with scapular fractures. The prevalence was similar across all anatomical regions of scapular fracture, with the exception of multiple fractures that showed a higher prevalence. The radial nerve accounted for the largest percentage of nerve injuries.

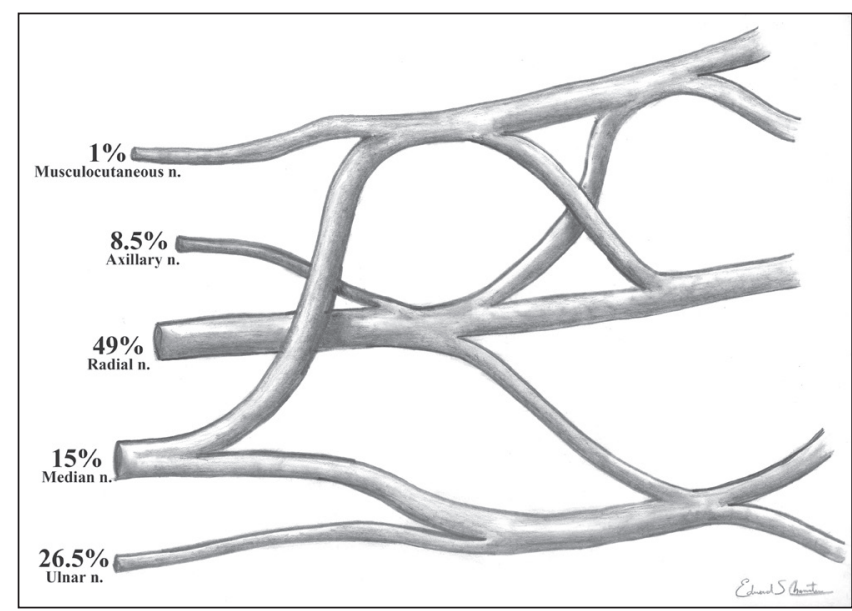

Figure 2) Percentage distribution of the 426 injuries to the five main branches of the brachial plexus. $n$ Nerve

ACKNOWLEDGEMENT: The NTDB remains the full and exclusive copyrighted property of the American College of Surgeons. The American College of Surgeons is not responsible for any claims arising from studies based on the original data, text, tables, or figures. In this study, we utilized the 2007, 2008, 2009, 2010 and 2011 versions of the database.

\section{REFERENCES}

1. Rowe CR. Fractures of the scapula. Surg Clin North Am 1963;43;1565-71.

2. Butters KP. The scapula. In: Rockwood CA, Matsen FA, eds. The Shoulder. Philadelphia: WB Saunders, 1990.

3. Ideberg R, Grevsten S, Larsson S. Epidemiology of scapular fractures. Incidence and classification of 338 fractures. Acta Orthop Scand 1995;66:395-7.

4. McGahan JP, Rab GT, Dublin A. Fractures of the scapula. J Trauma 1980;20:880-3.

5. Committee on Trauma, American College of Surgeons. National Trauma Data Bank (NTDB) Version X. Chicago, 2007-2011. $<$ https://www.ntdbdatacenter.com> (Accessed October 1, 2013).

6. Armstrong CP, Van der Spuy J. The fractured scapula: Importance and management based on a series of 62 patients. Injury 1984;15;324-9.

7. Scavenius M, Sloth C. Fractures of the scapula. Acta Orthop Belg 1996;62:129-32.

8. Thompson DA, Flynn TC, Miller PW, Fischer RP. The significance of scapular fractures. J Trauma 1985;25:974-7.

9. Berbaum KS, Brandser EA, Franken EA, Dorfman DD, Caldwell RT, Krupinski EA. Gaze dwell times on acute trauma injuries missed because of satisfaction of search. Acad Radiol 2001;8:304-14.

10. Imatani RJ. Fractures of the scapula: A review of 53 fractures. J Trauma 1975;15:473-8.

11. McGinnis M, Denton JR. Fractures of the scapula: A retrospective study of 40 fractured scapulae. J Trauma 1989;29:1488-93.

12. McGahan JP, Rab GT. Fracture of the acromion associated with an axillary nerve deficit: A case report and review of the literature. Clin Orthop Rel Res 1980;147:216-8.

13. Berbaum KS, El-Khoury GY, Franken EA, et al. Missed fractures resulting from satisfaction of search effect. Emerg Radiol 1994;1:242-9.

14. Berbaum KS, El-Khoury GY, Ohashi K, Schartz KM, Caldwell RT. Satisfaction of search in multitrauma patients: Severity of detected fractures. Acad Radiol 2007;14:711-22. 